This item was submitted to Loughborough's Research Repository by the author.

Items in Figshare are protected by copyright, with all rights reserved, unless otherwise indicated.

\title{
Designing and conducting online interviews to investigate interesting consumer phenomena
}

PLEASE CITE THE PUBLISHED VERSION

http://dx.doi.org/10.1108/13522750810879002

PUBLISHER

(C) Emerald Group Publishing Limited

VERSION

AM (Accepted Manuscript)

LICENCE

CC BY-NC-ND 4.0

\section{REPOSITORY RECORD}

Gruber, Thorsten, Isabelle Szmigin, Alexander E. Reppel, and Roediger Voss. 2019. "Designing and Conducting Online Interviews to Investigate Interesting Consumer Phenomena". figshare.

https://hdl.handle.net/2134/11931. 
This item was submitted to Loughborough's Institutional Repository (https://dspace.lboro.ac.uk/) by the author and is made available under the following Creative Commons Licence conditions.

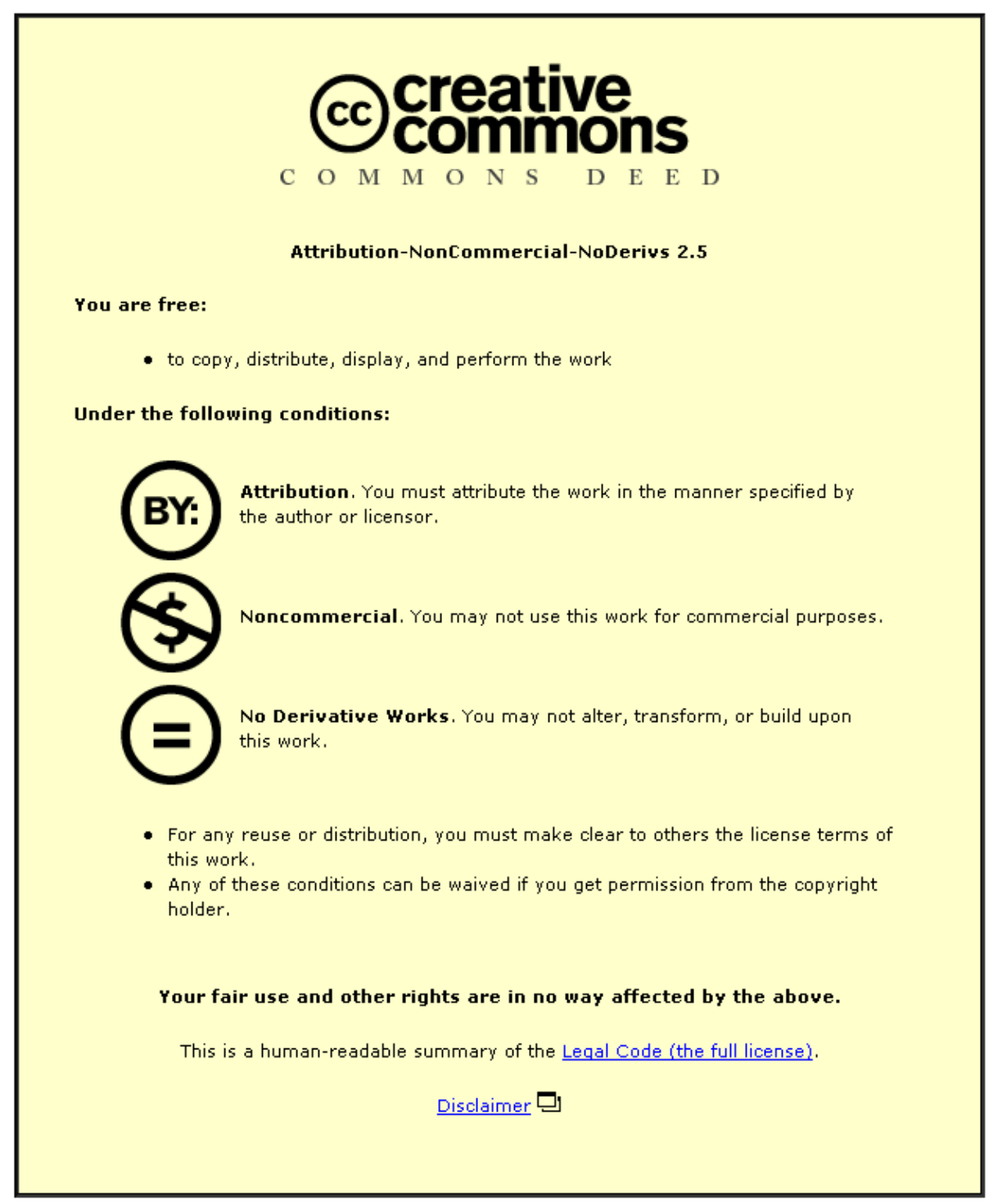

For the full text of this licence, please go to: http://creativecommons.org/licenses/by-nc-nd/2.5/ 


\title{
Designing and Conducting Online Interviews to Investigate Interesting Consumer Phenomena
}

Thorsten Gruber,

The University of Manchester

Manchester Business School

Isabelle Szmigin

The University of Birmingham

Birmingham Business School

\author{
Alexander Reppel \\ School of Management \\ Royal Holloway, University of London \\ Roediger Voss \\ University of Education Ludwigsburg \\ Pädagogische Hochschule Ludwigsburg \\ Institut für Bildungsmanagement
}

*Send correspondence to: Dr. Thorsten Gruber, The University of Manchester, Manchester

Business School, Booth Street West, Manchester M15 6PB, UK, Tel.: +44-(0)161-275 6479

(Email: thorsten.gruber@mbs.ac.uk) 


\section{Abstract}

Purpose - This paper thoroughly explains how qualitative researchers can design and conduct online interviews to investigate interesting consumer phenomena.

Design/Methodology/Approach - A semi-standardized qualitative technique called laddering was applied successfully to an online environment. Laddering allows researchers to reach deeper levels of reality and to reveal the reasons behind the reasons. A web survey that included an opinion leadership scale, filled in by 2,472 people, served as a springboard for identifying possible participants for the online laddering interviews. 22 online interviews were conducted with opinion leaders in the specific product field of digital music players such as Apple's iPod.

Findings - By conducting online interviews we were able to gather information from an interesting group of respondents that would have been difficult to contact otherwise. The whole online interviewing process was convenient for respondents who did not have to leave their homes and offices for the interviews. In general respondents enjoyed the online laddering interviewing experience and in particular the relaxed and friendly atmosphere. The most valued attributes of Apple's iPod are "control elements" and "design", which are linked to values such as hedonism and individuality.

Originality/value - The paper is the first to systematicallydescribe how qualitative researchers can conduct laddering interviews online. By explaining the online interviewing process in detail, we dispel criticism that qualitative research reports are often unclear, ambiguous and unstructured. Based on the detailed description of the online laddering process, other researchers can use the technique to get deeper insights into interesting consumer phenomena.

Keywords Qualitative research, Laddering, Internet, Interviews, Consumer research Paper Type Commentary Paper 
Designing and Conducting Online Interviews to Investigate Interesting Consumer Phenomena

\section{Introduction}

Qualitative researchers seek meaning and are particularly interested in the perspective and standpoint of the people they study (Hammersley, 1992). They want to get a deep understanding of social phenomena in context and interpret "phenomena in terms of the meanings people bring to them" (Denzin and Lincoln, 2003, p. 5). Interviewing is one of the most common and powerful methods which qualitative researchers use to understand other people (Fontana and Frey, 2003; Bryman, 2004). Interviews can be described as “conversation with a purpose” (Kahn and Cannell, 1957, p. 149; Dexter, 1970, p. 136; Burgess, 1984, p. 102), and qualitative researchers use interviews to gather information about a particular issue or topic. Interviews do not occur unintentionally but are consciously arranged and follow procedures and rules (Leonard, 2003). Qualitative researchers who use interviews as data collection tools believe that they can "investigate elements of the social by asking people to talk, and to gather or construct knowledge by listening to and interpreting what they say and to how they say it" (Mason, 2002, p. 225).

According to Leonard (2003), traditional face-to-face interviews, however, have several drawbacks: First of all, personal interviews can be quite laborious to arrange and to conduct. The transcription of interviews and the subsequent analysis of transcripts are time-consuming and demanding tasks. The whole interviewing process is also very costly to administer and interviewers may have to travel long distances to meet their respondents. Interviewees may also have to be paid for having travelled to the research site and for taking part in the project. While interviewers should record information in an unbiased way, they may still have expectations about what interviewees feel or know about the topic, similarly beliefs, based on respondents' appearance or background, may have an impact on the quality of the interviews. Furthermore, interviewers have to be skilful at using the techniques of prompting and probing 
as they could otherwise influence respondents to give a hoped-for answer. Similarly, interviewees may be influenced by the interviewer's visible characteristics like age, race, gender, physical appearance and conduct and may try to give answers they think interviewers want to hear. We believe that such drawbacks of the traditional interview method could be reduced significantly in an online environment.

\section{Benefits of conducting online interviews}

Although several qualitative researchers have discovered the usefulness of the internet to design and conduct qualitative research projects and online data collection methods are increasingly used, authors such as Comley (2002) rightly point out that researchers have been accepting online qualitative research at a significantly slower pace than online quantitative research. Similarly, O'Connor and Madge (2003) maintain that the topic of online qualitative research in general and the issue of conducting qualitative online interviews in particular should attract more attention. Up to now, the focus in the online qualitative research literature has been mainly on online focus groups (Bryman, 2004), reflecting the important role and frequent use of this qualitative research method (e.g. Boddy, 2005; Herington et al., 2005; Stokes and Bergin, 2006). According to Pincott and Branthwaite (2000, p. 151), however, the advantages of conducting qualitative research on the internet are "more apparent in online individual interviews (one-to-one) than in online group discussions”. Interviewers can for example create rapport more easily during individual online interviews than during online group discussions. In one-to one interviews, both interviewer and interviewee have equal status while interviewers play a dominant role in online groups.

Online interviews are also cheaper to conduct than traditional interviews as there are no travel, venue renting and accommodation expenses. Researchers do not have to tape and transcribe online interviews as the online chat programmes that are used to conduct interviews automatically generate interview transcripts, which allow a quicker analysis of data. Further, 
the whole interviewing process may be less stressful and more convenient for respondents as they can be interviewed at home or at work in a familiar and non-threatening environment. The anonymous interviewing situation means that respondents are not influenced by the interviewers' appearance, tone of voice and body language. Thus, social desirability bias and especially interviewer/interviewee bias should not occur (Duffy et al., 2005; Miller and Dickson, 2001).

According to Joinson (2001) respondents also reveal more personal information in computer-mediated communication than in traditional face-to-face discussions due to visual anonymity and higher levels of private self-awareness. Similarly, Hanna et al. (2005) found that respondents are more likely to express their deeper feelings in an online environment than during traditional interviews. As respondents are also less inhibited online, they are willing to state their opinions more directly than in a traditional interviewing environment (Tse, 1999; Pincott and Branthwaite, 2000; Sweet, 2001).

As online interviewees can revise their answers before they send them off, online responses are grammatically better than statements in face-to-face interviews (Folkman Curasi, 2001). As the flow of conversion of online interviews, which are conducted in rounds, is broken into text "chunks" with a time-lag between questions and answers, online interviews are also more ordered and structured than traditional face-to-face interviews (Chen and Hinton, 1999).

\section{The Apple iPod phenomenon}

Another benefit of online qualitative research is that it allows researchers to sample minority and professional groups that would otherwise be difficult to contact (Pincott and Branthwaite, 2000; Langer and Beckman, 2005). For example people who spend much of their free time online may not be willing to have personal face-to-face interviews with researchers but may be interested in online interviews. Miller and Dickson (2001, p. 146) support this view by 
saying that online qualitative research is appropriate "when the target population is small, very specialized in its skills, and difficult to find and recruit, and when the issue relates to high-tech products and services".

This is especially true for users of Apple's digital music player "iPod". Users of the iPod are an interesting group of consumers as they are highly involved with the brand (Belk and Tumbat, 2005) and regarded as a consumer subculture (Schouten and McAlexander, 1995). According to a recent Forrester report (Collingwood, 2005), the iPod accounts for around three quarters of the digital music player market in the United States. This is an impressive achievement for a company that introduced the original iPod into a difficult market environment at the end of 2001. The iPod, was neither the first digital music player, nor initially compatible with the majority of personal computers, only being able to be used with Apple's own Macintosh computers, a platform accounting for less than $4 \%$ of US computer sales (Belk and Tumbat, 2005). Significantly Apple extended the iPod market from the group of early adopters to the early majority "without diminishing the product's cool factor" (Olson et al., 2005, p. 14), those aspects of a product or brand of particular importance to the small but influential segment of innovators and early adaptors.

We therefore decided to conduct online interviews with iPod users to learn more about the iPod phenomenon in general and about the preferred attributes of the iPod player in particular.

We believe that our chosen online approach is particularly appropriate for researching the iPod for a variety of reasons; music can only be downloaded onto the digital music player through a computer using Apple's iTunes software, iPod users purchase music through Apple's 'iTunes' online music store and for this purpose they generally need an internet connection. Moreover, as stated above, this group of respondents with their particular interest in high tech products would have been difficult to contact otherwise. 
In the following, we describe how qualitative researchers can design and conduct online interviews to investigate interesting consumer phenomena such as the Apple iPod. Given the current lack of knowledge regarding the iPod phenomenon we decided to apply the established qualitative laddering technique (Reynolds and Gutman, 1988) to an online environment as it allows researchers to reveal the "reasons behind the reasons" (Gengler $e t$ $a l ., 1999$, p. 175) and as it is commonly used in exploratory qualitative phases of research projects (e.g. Botschen et al., 1999; Devlin et al., 2003; Zanoli and Naspetti, 2002). With the qualitative laddering technique we aim to get a deeper understanding of the preferred product attributes of the iPod to reveal underlying consumer benefits of and preferences for this innovative brand.

The main aim of the paper is to explain the online laddering interviewing process in detail, as qualitative researchers are often criticised for their unclear and ambiguous research reports. Difficulties include, not explaining how the research was conducted, why a certain research method was applied, how respondents were selected, how data was analysed, and conclusions reached (Bryman, 2004). While qualitative research is less structured and rule driven than quantitative research, this does not preclude the standardisation of data collection and analysis such that it is comprehensible to other researchers who may want to continue or replicate the study. In this connection, Reynolds et al. (2001) point out that the laddering method can be distinguished from typical qualitative research methods in the following way: the laddering technique has a definite structure as interviewers use standard probing questions, follow an explicit agenda, and the questioning flows in much the same way for each interview. Reynolds et al. (2001) contrast the typical qualitative structure as being shallow and broad with the results from laddering which are deep and focused. Thus, the laddering method can be described as a structured qualitative method that leads to deep and focused results. By explaining the different stages of the online laddering process thoroughly, we hope that fellow researchers will become interested in using this technique in their research projects. 


\section{The laddering interviewing technique}

Laddering interviews attempt to discover the salient meanings that consumers associate with products, services and behaviours and to reveal so-called means-end chains. The focus is on the associations in the consumer's mind between the attributes of products, services or behaviours, which are the "means", the consequences of these attributes for the consumer, and the personal values or beliefs, the "ends", which are satisfied by the consequences. While the attributes are the characteristics of a product or service, the consequences are the reasons why an attribute is important. They are the psychological or physiological aspects which motivate a customer to use a product or service (Gutman, 1982). Values are a more universal concept and may be considered as life goals; personal and general consequences individuals are striving for in their lives (Rokeach, 1973). The linkages between attributes, consequences and values are what produce the means-end chains (Peter et al., 1999). Consumer knowledge is assumed to be hierarchically organized in the consumer's memory spanning different levels of abstraction (Reynolds et al., 1995); the higher the level of abstraction, the stronger the connection to the self. Thus a hierarchy exists with attributes (low level of abstraction) as less relevant to the self than consequences (mid level of abstraction) and values being of most relevance (high level of abstraction) (Olson and Reynolds, 1983).

The means-end approach has its roots in Kelly's Personal Construct Psychology (1991/1955). According to Kelly, individuals have their own view of the world and are probably capable of reflecting on and controlling their behaviour by creating rules or developing theories. Similar to Kelly's approach, a means-end researcher follows the "personas-scientist" analogy and believes "that consumers' means-end chains represent their personal theories of how aspects of the physical world relate to their lives" (Gengler et al., 1995, p. 254).

The laddering technique emerged in the clinical psychology area introduced by Dennis Hinkle (1965) to model the concepts and beliefs of people. In a market research context, the 
technique was first used for product or brand positioning issues and to link the consumer's product knowledge to his/her self-knowledge (Gutman, 1982; Olson and Reynolds, 1983). More recently, the laddering technique, however, has also been applied to a range of areas including sales management (e.g. Botschen et al., 1999; Deeter-Schmelz et al., 2002; Reynolds et al., 2001), and strategic marketing (e.g. Norton and Reynolds, 2001; Reynolds and Rochon, 2001), and consumer behaviour (e.g. Bagozzi and Dabholkar, 1994; Pieters et al., 1995; Pieters et al., 1998; Vriens and Hofstede, 2000; Wansink, 2000, 2003). Laddering is normally done in person and involves semi-standardized in-depth interviews, where respondents are restricted as little as possible in their natural flow of speech

All laddering interviews consist of an elicitation and laddering stage (Grunert and Grunert, 1995). Initially an elicitation stage which may use techniques such as triadic sorting, direct elicitation or free sorting to derive preference based distinction criteria is undertaken. Criteria thus derived act as the starting point for the laddering probes, which should eventually uncover attribute-consequence-value chains. This is achieved through repeatedly asking questions as to why an attribute/consequence/value is important to the respondent with the answer serving as the starting point for the next question. Interviewers use these probe questions to reveal attribute-consequence-value chains by taking the subject up a so called "ladder of abstraction" (hence the name "laddering"), starting with concrete attributes and ending with abstract values. The laddering process continues until the respondent gives either circular answers, is incapable or reluctant to answer or reaches a terminal value (Claeys et al., 1995).The following figure illustrates such a ladder of abstraction:

"Take in figure 1" 


\section{Conducting laddering interviews online}

Laddering interviews can be conducted online in the form of text-, audio- or video-chats. As we preferred not to transcribe our laddering interviews manually, we decided not to use videographic methods (Belk and Kozinets, 2005) but to conduct text based online laddering interviews using instant messenger software such as AIM or MSN Messenger that produce transcripts automatically. Text-based online chats are conducted in rounds: After some introductory words (thanking the respondent for taking part in the interview, introducing oneself and the aim of the research project, and assuring anonymity and confidentiality) the interviewer can start the online laddering interview by typing the first question in a small text box of the chat software. By clicking a "send button", the question is immediately sent to the interviewee who can read the question in a larger text box. The interviewee can then send an answer to the interviewer the same way. The next section describes how we used a quantitative web survey to draw our sample of respondents for the online laddering interviews.

\section{The research process - Identification of participants}

Grunert and Grunert (1995) suggest that researchers should collect ladders that are from a homogeneous group of respondents. A suitable approach for identifying an appropriate group of homogeneous respondents is the selection of opinion leaders. Because opinion leaders exercise informal influence upon other peoples' behaviours and attitudes through productrelated conversations (Goldsmith and De Witt, 2003), they are considered attractive targets for marketing communication (Stern and Gould, 1988), as well as for the adoption and diffusion of newly developed products (Chan and Misra, 1990). Providing information or advice perceived as more credible than mass advertising, opinion leaders can informally influence others' attitudes and behaviours (Stern and Gould, 1988). Opinion leaders are particularly important for the success of innovative products, as when they are among the 
early adopters themselves, they pass on important information to opinion seekers (Flynn et al., 1996). We also believed that opinion leaders would be highly motivated and willing to invest sufficient time for taking part in our online interviews.

Concerning minimum sample size, Reynolds et al. (2001) recommend that, as a rule of thumb, researchers should interview at least 20 respondents. This sample size could already give interviewers a significant understanding of the main attributes, consequences, and values of products, services or people. Thus, we decided to draw our sample of at least 20 respondents for the online laddering interviews from a group of opinion leaders in the specific product field of digital music players such as Apple's iPod.

Following Creswell (2003, p. 4) who believes that the idea of applying only quantitative or qualitative methods "falls short of the major approaches being used today in the social and human sciences", we decided to employ a quantitative web survey to identify suitable respondents for the following qualitative laddering interviews. The web survey served "as a springboard for identifying possible participants" (Bryman, 2004, p. 475).

During May 2005, the three German researchers of this project invited German-speaking users of the Apple iPod music player to fill in our web survey. For this purpose, we posted invitations to fill in our survey on several websites that iPod users frequently visit such as

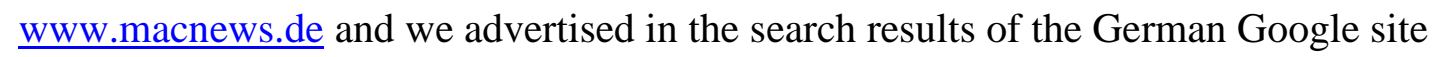
(www.google.de). The purpose was to make potential respondents aware of the website we created for this research project (www.ipodstudies.com) that hosted the questionnaire. The web survey included an opinion leadership scale that was originally constructed by Flynn et al. (1996) consisting of six items to identify the desired homogeneous group of opinion leaders. Our scale was adjusted by including a 'no answer' option to exclude those participants who would otherwise only consider the end points of the scale. We also scaled the six items from 1 to 5, with a higher number meaning stronger agreement. The Cronbach's alpha reliability coefficient for our opinion leadership scale was .73. 
The web survey also covered the following topics: satisfaction with the iPod in general and with its product attributes in particular (e.g. design, usability etc.), importance of iPod product attributes, and the reasons for choosing the iPod. Respondents were also asked how much time they would spend daily listening to music and for which music groups Apple should launch a new iPod special edition. We also included a question concerning usage of instant messenger software (e.g. iChat, AIM, MSN Messenger, ICQ). Finally, we asked respondents whether they would be interested in being contacted for another research project. For this purpose they had to give us a valid email address. However, we also gave respondents the possibility of creating an anonymous e-mail for the research project purpose only.

Cobanoglu and Cobanoglu (2003) suggest that researchers using web surveys should use incentives to achieve good response rates. They recommend that researchers should offer a small prize to all respondents and also enter them into a raffle for a bigger prize. Following Cobanoglu and Cobanoglu, all respondents who filled in the web survey could download two exclusive chapters (78 pages in total) of an iPod book. They were also included in a draw for prizes such as a computer, audio books, sound systems, and personalised protective covers for the iPod.

“Take in figure 2"

Figure 1 shows that a total of 2,472 people participated in our web survey and 2,178 (88\% out of 2,472 ) of them provided complete answers to the opinion leadership scale. From the 317 respondents that scored highest on this scale, 273 (86\% out of 317) agreed to be contacted for a further study and 198 of them were not only opinion leaders but also owners of an iPod and regular users of instant messenger software. From this group we randomly chose 85 
respondents for the online laddering interviews, the remaining respondents were invited for another research project.

For our online interviews, we then contacted respondents by email and thanked them for having taken part in the web survey and for being interested in the new research project. We then informed them that this new project was concerned with identifying the attributes of the iPod that they valued the most. Further, we told respondents that we were particularly interested in their views as opinion leaders with regard to digital music players. We then informed them that the new project would be conducted in the form of an online interview that would last for approx. 60 minutes. We also promised participants an issue of an iPod magazine and a protective cover for their iPod as a further reward for taking part in the research study.

Respondents were able to schedule their own interview appointment via our homepage. For this purpose we used an online appointment scheduling software that allowed respondents not only to view and edit their own appointments online but also to change or cancel appointments if necessary. Participants had to provide the following information: email address, chat name, date and time of online interview and the name of the preferred chat software (iChat, AIM, MSN Messenger, ICQ etc.).

We originally planned to conduct as many interviews as possible with the 85 potential respondents and to analyse the results after every ten interviews. After twenty interviews, it was evident that our categories had reached theoretical saturation, i.e. no new or relevant data concerning categories was emerging and the categories and linkages between categories were well-established (Strauss and Corbin, 1998). We therefore decided that no additional interviews were necessary, so the laddering process was completed with 22 interviews. 


\section{The online laddering interviewing process}

In the following, the online laddering interviewing process is explained thoroughly. In order to understand the laddering process better we divided it into three stages: a pre-laddering interview phase, an online laddering interview phase, and a post-online laddering interview phase.

\section{The pre-online laddering interview phase}

Based on the information gathered from the web survey, we prepared for all respondents "participation cards", which were information sheets containing e-mail addresses, age, and gender of the respondents, their current iPod models, favoured music groups, and recommended new iPod special editions, preferred circumstances for using the iPod, and the time they spend daily listening to music in general and using their iPod in particular. The day before an online interview took place, we reminded participants by e-mail and told them that we were looking forward to meeting them online. In this e-mail we also mentioned the scheduled interview appointment, the chat name of the interviewer, and the name of the chat software that the respondent selected. This "reminder" email was necessary to make sure that all respondents knew who would contact them the next day.

Before an online laddering interview started, we studied the respondent's participation card to be better prepared for the interview. We then knew for example which music group the interviewee favoured and how much time he or she spends every day with the iPod. We also opened a word document with prepared standardised text modules such as "My name is..." for the opening of each interview and modules such as "Please follow the following link to download your issue of the iPod magazine" for the ending of the interview to fasten the whole process. As soon as respondents were online and ready for the online interview, we immediately contacted them by typing "Hello Mr/Ms ..." in a small text box of the chat software. By clicking a "send button", our message was immediately sent to the interviewees 
who could read it in a larger text box. Interviewees could then send an answer back to us the same way. We then thanked respondents for taking part in the interview and introduced ourselves and the aim of the research project. Following that, we promised all interviewees that we would use the information for research purposes only, it would not be used commercially, and we assured confidentiality.

Coolen and Hoekstra (2001) suggest that interviewers conducting laddering interviews should create a non-threatening interview environment so that respondents can talk freely about their motivations. Respondents should get the impression that their opinion is important and that there are no right or wrong answers. The interviewer should only act as a facilitator “who has to keep the respondent talking" (Coolen and Hoekstra 2001, p. 296). Thus, we assured respondents that they could not give any wrong answers, that we would not judge their answers, and that they could use colloquial language or even slang to tell their stories. We also told them that we would be particularly interested in their expert opinions on this topic.

Reynolds et al. (2001) recommend that interviewers should start with warm-up questions to put interviewees at ease before the actual laddering interview begins, this we did at the beginning of each interview. As our study combines a quantitative web survey with the qualitative laddering process, we were able to refer to information from the initial questionnaire such as respondent's answers to questions like "For which music group or person should Apple introduce an iPod special edition?" and "When and in what circumstances do you like to use your iPod the most?" The idea behind this 'small-talk' was to break the ice and create rapport so that respondents felt comfortable and were prepared for the following interview. By having this informal chat, we not only tried to establish a relationship with the respondents and to encourage them to take part in the interview but we also prepared ourselves for the interview through this 'warm up'. 
The online laddering interview phase

After the warm up session, the actual laddering interviewing process began which consisted of two stages: elicitation of attributes and the laddering process. Researchers use elicitation techniques (e.g. triadic sorting, free sorting, direct elicitation, ranking and picking) to derive criteria that can discriminate between products or services or behaviours. Respondents normally have to perform a sorting or ranking task so that a preference-based distinction can be revealed. Alternatively, interviewers may directly ask respondents which attributes or characteristics are of relevance for them. Bech-Larsen and Nielsen (1999) who compared five techniques for elicitation of attributes found that "complex methods like triadic sorting are more time-consuming, and that they do not in any way outperform the less complex free sorting technique" (p.338-339). Therefore, simple techniques like direct questioning and ranking are sufficient to elicit salient attributes or characteristics. Thus, we directly asked all 22 interviewees to tell us three or four attributes of the iPod that would be of relevance for them and that distinguish the iPod from its competitors.

In the second stage, the derived criteria from stage 1 were the starting point for the laddering probes which should uncover the complete means-end structure. For this, we began with the attribute of the iPod that respondents considered to be the most important and asked: "Why is attribute xyz important to you?" The answer to this question served as the starting point for further questioning. The following table illustrates an extract from one online interview:

\section{"Take in table I"}

We continued with the laddering process until respondents gave either circular answers, were incapable or reluctant to answer or reached the value level. As the laddering interview is a 
semi-structured interview it allows for flexibility and interviewees occasionally mentioned new attributes which we also addressed during the interview.

Although all respondents were able to climb the ladder of abstraction, which means that all interviewees were capable of associating attributes with consequences and consequences with values, they sometimes had difficulties with climbing the ladder of abstraction any further during the interview. In these cases, we applied several of the techniques recommended by Reynolds and Gutman (1988) to facilitate the interview. For example, we asked them how they would feel if the iPod was not easy to use or if the design was not attractive. We also asked respondents to think back in time to their feelings when they used their iPod. We occasionally repeated what respondents had just written to check if we had understood the respondents' answers correctly.

If interviewees did not give sufficient answers, we employed probes to gather additional and/or more detailed information. We asked for example "Could you please give me more information about...". We also asked respondents to clarify certain answers, particularly if their responses were ambiguous. In addition, we related respondents' answers to previous answers and asked interviewees if these connections were valid. While applying these techniques, we tried not to push respondents up the ladder of abstraction but to accompany them on their way up the ladder. It was important for us to find a balance between helping respondents and avoiding influencing their answers.

It was important to maintain rapport during the interview. This can be accompolished by personalising the encounter, which is possible to achieve by adapting interpersonally and "altering various interpersonal communication elements (e.g. tone of voice, vocabulary, gestures) to meet what they perceive to be the unique needs of individual consumers" (Bettencourt and Gwinner 1996, p. 3). We attempted to adapt interpersonally in an online environment by using language that was comprehendible and relevant to our respondents. Further, if interviewees frequently used emoticons to communicate their feelings, we also 
used them. If interviewees appeared to have lots of time and were chatty, we also took our time. Similarly, if interviewees seemed to be in a rush, we tried to complete the laddering process as quickly as possible. We believe that a personal connection can only develop online if both exchange partners indicate a genuine interest in the other person, which means that both parties actively participate and exchange information during the online encounter. We therefore tried to listen as actively as possible to what respondents were writing and attempted to remain focused and pay attention during the entire interviews.

\section{The post-online laddering interview phase}

After each interview, we thanked respondents again for their participation in the interview and for giving up their time. We then gave them a web address to download the promised issue of the iPod magazine and we informed respondents that we could send them the study results if interested. Finally, we asked them to give us a delivery address to ship the iPod protective cover and to visit another website to fill in a feedback form.

13 respondents gave us constructive feedback. They particularly enjoyed the friendliness of the interviewers, the relaxed atmosphere, and the interesting and well-founded questions. They also liked the idea of having a personalised interview in a normally impersonal online environment and preferred it to having a telephone or face-to-face interview. Respondents also enjoyed the fact that the online interview did not focus on the preferred attributes of iPod solely but was concerned with broader topics to get a deeper understanding of the iPod phenomenon. Only two respondents mentioned drawbacks of the online interviewing experience and they criticised the length of the interview itself and the long interval between questions and answers. Respondents also suggested that interviewers should be quicker typists and that the whole interview should be shorter. Respondents also asked to be informed at the beginning of the chat how long the interview would take and what issues would be discussed. Our online laddering interviews lasted between 50 and 140 minutes in comparison to 
traditional laddering interviews that normally last between 45 to 120 minutes (Reynolds et al., 2001).

Finally, respondents were asked to mark the online laddering interviewing experience according to a 6 point scale running from 1 (very satisfactory) to 6 (very unsatisfactory). The overall average grade was 1.6 (very good), which indicates that respondents genuinely enjoyed the online laddering interviewing experience.

\section{Data analysis and results}

As the main aim of this paper is to explain thoroughly the process of how to design and conduct qualitative online interviews to investigate interesting consumer phenomena, we will only briefly describe the analysis of the laddering data and the research findings.

We used the software program LADDERMAP (Gengler and Reynolds, 1993) to content analyse the ladders from the online interviews. Coding was an iterative exercise of recoding data, splitting, combining categories, generating new or dropping existing categories. Codes for individual means-end chains were aggregated and expressed in an implications matrix which details the associations between the constructs. The implications matrix shows the number of times one code leads to another. Finally, a graphical representation of the aggregate chains was presented in a Hierarchical Value Map (HVM). The map consists of nodes, which stand for the most important attributes/consequences/values and lines, which represent the linkages between the concepts. The following figure illustrates the HVM based on the online laddering interviews

\section{"Take in figure 3 "}

The size of the circle stands for the frequency respondents brought up a certain concept. Thus, the most important attributes identified are "control elements", which includes the iPod's 
'click wheel' control and the menu navigation, and "design". The thickness of the line that links concepts represents the relative frequency of association between the concepts of meaning. Thus, the attribute "control elements" is for example strongly linked with the consequence "ease of use" and the value "feeling good". The iPod's design satisfies user's desire for beauty and helps them to feel individual. Respondents also value the iPod's good sound quality that allows them to enjoy music and to relax. The iPod's ease of use and simplicity also helps users relax and enjoy life and have fun ("hedonism"). In addition, users can then save time, which allows them to devote attention to other issues ("concentrate on other issues"). Further, the iPod's reliability creates a feeling of security.

\section{Limitations of online laddering interviewing}

There are several limitations to conducting online laddering interviews which researchers interested in the research method should consider. A major disadvantage of text based online laddering interviews is the loss of all non-verbal communication cues making it difficult for interviewers to create rapport (Chen and Hinton, 1999; Folkman Curasi, 2001; O'Connor and Madge, 2003) and such rapport is important to establish a relationship with respondents who are then willing to share information (Bryman, 2004). Interviewers cannot receive and interpret respondents' non-verbal cues (body language, facial expressions, promimics) and they also cannot send non-verbal cues (e.g. head nodding, murmurs of approval, and smiling) to assure respondents that listening has occurred and to achieve rapport. In an online environment, interviewers are limited to use of so called "emoticons" such as $;$ to communicate friendliness or other responses but they can also make some online introductory small talk at the beginning of the interview to put respondents at ease.

Researchers conducting online laddering interviewers are not able to observe if respondents are losing interest in the conversation or if they are annoyed or unclear about a particular question. Interviewers in an online environment cannot be sure whether their 
respondents remain focused all the time during the interview or become distracted (Comley, 2002; O'Connor and Madge, 2003) and so it may be difficult for researchers to control the success of online interviews (Folkman Curasi, 2001).

Online laddering interviews require motivated respondents who have to invest time and money for an online interview. These interviews are also physically more demanding than traditional face-to-face interviews as respondents continuously have to type, look at a computer monitor, and think about their answers before typing (Chen and Hinton, 1999; O’Connor and Madge, 2003). Therefore online laddering interviews may not be suitable for respondents who do not possess good typing skills as they may feel under constant time pressure to give quick answers and may decide to shorten answers. Similarly, interviewers need to type quickly or work together with a second interviewer (Sweet 2001; O'Connor and Madge, 2003) to ensure respondents do not have to wait too long for the next question to appear. These problems may be of particular relevance for certain respondents who are not used to an online environment or have difficulty typing. Higher incentives may be used to compensate for some of the issues discussed above (Tse, 1999) but clearly online interviews will not suite all respondents.

Researchers using the laddering technique should also be aware of the fact that departures from the "ideal" laddering interview exist (Grunert and Grunert (1995). Some respondents may not always give simple answers to the standard laddering probe "Why is attribute/ consequence/value xyz important to you?" but tell little stories (The last time I went to England I found..., and I met, and then etc.), add details, or jump around from one category to another. Some other respondents may be unable to climb the ladder of abstraction any higher even if they are only at the attribute or consequences level. These behaviours raise a number of issues for the interviewer. Should they press the respondent to give an additional answer? When should they stop probing? This is one of the most difficult aspects of conducting laddering interviews as it is not always clear for the interviewer when to stop the laddering 
process. Ultimately interviewers have to find a balance between helping respondents to climb up the ladder while avoiding influencing their answers.

Finally, all personal construct approaches depend on the respondents' willingness and ability to reflect on their knowledge, reveal their individuality, and verbalize their experiences. Banister et al. (1994), however, believe that respondents may have difficulties with verbalizing their experiences and to reflect on their attitudes and behaviors. In this connection, Veludo-de-Oliveira et al. (2006, p. 303) suggest that interviewers should ask respondents "to give examples and to make analogies. It will help them to go up to different levels of abstraction".

\section{Conclusion}

This paper has shown how the established laddering interviewing technique can be applied successfully to an online environment. Online laddering interviews allow an inexpensive and fast collection of laddering data. There is no need to tape and transcribe interviews as the online chat software automatically generates interview transcripts, which allows a quick data analysis. Further, online interviews enable interviewers to capture all provided information and to follow each elicited attribute even if respondents mentioned several aspects at the same time.

By using an initial web survey, we were not only able to sample a homogeneous and motivated group of respondents for the following online laddering interviews but also to prepare "participation cards". These cards contained important information about participants that enabled interviewers to create rapport and to put them at ease at the beginning of each interview.

Moreover, by conducting online interviews we were able to gather information from an interesting group of respondents that would have been difficult to contact otherwise. We had online interviews with politicians, professors, musicians, students, actors, and entrepreneurs. 
All interviewees had one thing in common; they were all opinion leaders and owners of an iPod and therefore represented a homogeneous group.

The whole online interviewing process was convenient for respondents who did not have to leave their homes and offices for the interviews. In addition, neither the appearance of the interviewers nor their tone of voice or body language influenced respondents' answers due to the faceless interviewing situation. Finally, respondents gave us very positive feedback. They enjoyed the online laddering interviewing experience in general and the relaxed and friendly atmosphere in particular. Our experience of conducting online interviews has also revealed some of the difficulties of this type of research and we suggest that it may only be successful with certain types of respondents and also requires particular skills of the interviewers.

After having explained in detail how laddering interviews can be conducted online we hope that fellow researchers develop further studies that use online laddering to investigate interesting consumer phenomena. 


\section{References}

Bagozzi, R. P. and Dabholkar, P. A. (1994), "Consumer recycling goals and their effect on decisions to recycle: a means-end chain analysis", Psychology \& Marketing, Vol. 11 No. 4, pp. 313-40.

Banister, P., Burman, E., Parker, I., Taylor, M. and Tindall, C. (1994), Qualitative Methods in Psychology - A Research Guide, Open University Press, Maidenhead.

Bech-Larsen, T. and Nielsen, N. A. (1999), “A comparison of five elicitation techniques for elicitation of attributes of low involvement products", Journal of Economic Psychology, 20, pp. 315-341.

Belk, R. W. and Kozinets, R. V. (2005), "Videography in marketing and consumer research”, Qualitative Market Research, Vol. 8 No. 2, pp. 128-141.

Belk, R. W. and Tumbat, G. (2005), “The cult of Macintosh", Consumption, Markets and Culture, Vol. 8 No. 3, pp. 205-17.

Bettencourt, L. A. and Gwinner, K. (1996), “Customization of the service experience: the role of the frontline employee", International Journal of Service Industry Management, Vol. 7 No. 2, pp. 3-20.

Boddy, C. (2005), "A rose by any other name may smell as sweet but "group discussions" is not another name for a "focus group" nor should it be", Qualitative Market Research, Vol. 8 No 3, pp. 248-55.

Botschen, G., Thelen, E. M. and Pieters, R. (1999), “Using means-end structures for benefit segmentation”, European Journal of Marketing, Vol. 33 No. 1/2, pp. 38-58.

Bryman, A. (2004), Social Research Methods, 2nd ed., Oxford University Press, Oxford.

Burgess, R.G. (1984), In the Field: An Introduction to Field Research, Allen \& Unwin, London.

Chan, K. K. and Misra, S. (1990), "Characteristics of the opinion leader: a new dimension", Journal of Advertising, Vol. 19 No. 3, pp. 53-60. 
Chen, P. and Hinton, S. M. (1999), ’Realtime interviewing using the world wide web”, Sociological Research Online, Vol. 4 No. 3. Available (14. December 2005) http://www.socresonline.org.uk/ socresonline/4/3/chen.html.

Claeys, C., Swinnen, A. and Vanden Abeele, P. (1995), “Consumers' means-end chains for "think" and "feel” products", International Journal of Research in Marketing, Vol. 12, pp. 193-208.

Cobanoglu, C. and Cobanoglu, N. (2003), "The effect of incentives in web surveys: application and ethical considerations", International Journal of Market Research, Vol. 45 No. 4, pp. 475-488.

Collingwood, H. (2005), “The five rules of cool”, FORRESTER Research, Cambridge, Mass. Available (14. December 2005) http://www.forrester.com/magazine/ articles.003/03.apple.r2.pdf.

Comley, P. (2002), “Online survey techniques: current issues and future trends", Interactive Marketing, Vol. 4 No. 2, pp. 156-169.

Coolen, H. and Hoekstra, J. (2001), "Values as determinants of preferences for housing attributes", Journal of Housing and the Built Environment, Vol. 16 No. 3-4, pp. 285-306.

Creswell, J. W. (2003), Research Design-Qualitative, Quantitative, and Mixed Methods Approaches, 2nd ed., Sage, Thousand Oaks, CA.

Deeter-Schmelz, D. R., Kennedy, K. N. and Goebel, D. J. (2002), “Understanding sales manager effectiveness - linking attributes to sales force values", Industrial Marketing Management, Vol. 31 No. 7, pp. 617-626.

Denzin, N. K. and Lincoln, Y. S. (2003), “The discipline and practice of qualitative research”, in Denzin, N. K and Lincoln, Y. S. (Eds.), The Landscape of Qualitative ResearchTheories and Issues, Sage, Thousand Oaks, CA, pp. 1-45.

Devlin, D., Birtwistle, G. and Macedo, N. (2003), "Food retail positioning strategy: a meansend chain analysis", British Food Journal, Vol. 105 No. 9, pp. 653-670 
Dexter, L. W. (1970), Elite and Specialized Interviewing, Northwestern University Press, Evanston.

Duffy, B., Smith, K., Terhanian, G. and Bremer, J. (2005), “Comparing data from online and face-to-face surveys", International Journal of Market Research, Vol. 47 No. 6, pp. 615639.

Flynn, L. R., Goldsmith, R. E. and Eastman, J. K. (1996), “Opinion leaders and opinions seekers: two new measurement scales", Journal of the Academy of Marketing Science, Vol. 24 No. 2, pp. 137-47.

Folkman Curasi, C. (2001), “A critical exploration of face-to-face interviewing vs. computermediated interviewing”, International Journal of Market Research, Vol. 43 No. 4, pp. $361-375$.

Fontana, A. and Frey, J. H. (2003), "The interview - from structured questions to negotiated text", in Denzin, N. K. and Lincoln, Y. S. (Eds.), Collecting and Interpreting Qualitative Materials, 2nd ed., Sage, Thousand Oaks, CA, pp. 61- 106

Gengler, C. E. and Reynolds, T. J. (1993), LADDERMAP: A Software Tool for Analyzing Laddering Data.

Gengler, C. E., Klenosky, D. B. and Mulvey, M. S. (1995), "Improving the graphic representation of means-end results", International Journal of Research in Marketing, Vol. 12 No. 3, pp. 245-256.

Gengler, C. E., Mulvey, M. S. and Oglethorpe, J. E. (1999), “A means-end analysis of mothers' infant feeding choices", Journal of Public Policy \& Marketing, Vol. 18 No. 2, pp. 172-88.

Goldsmith, R. E. and De Witt, T. S. (2003), “The predictive validity of an opinion leadership scale", Journal of Marketing Theory \& Practice, Vol. 11 No. 1, pp. 28-35. 
Grunert, K. G. and Grunert, S. C. (1995), "Measuring subjective meaning structures by the laddering method: theoretical considerations and methodological problems", International Journal of Research in Marketing, Vol. 12, pp. 209-25.

Gutman, J. (1982), “A means-end chain model based on consumer categorization processes”, Journal of Marketing, Vol. 46, pp. 60-72.

Hammersley, M. (1992), What's Wrong with Ethnography?, Routledge, London.

Hanna, R. C., Weinberg, B., Dant, R. P. and Berger, P. D. (2005), "Do internet-based surveys increase personal self-disclosure?", Database Marketing \& Customer Strategy Management, Vol. 12 No. 4, pp. 342-356.

Herington, C., Scott, D. and Johnson, L. W. (2005), "Focus group exploration of firmemployee relationship strength", Qualitative Market Research, Vol. 8 No 3, pp. 256-76.

Hinkle, D. (1965), "The change of personal constructs from the viewpoint of theory of construct implications", Unpublished PhD thesis, Ohio State University, Athens, OH, cited in Bannister, D., \& Mair, J. M. M. (1968), The evaluation of personal constructs, Academy Press, London.

Joinson, A. N. (2001), "Self-disclosure in computer-mediated communication: the role of selfawareness and visual anonymity", European Journal of Social Psychology, Vol. 31, pp. 177-192.

Kahn, R. L. and Cannell, C. F. (1957), The Dynamics of Interviewing: Theory, Technique, and Cases, New York, NY, Wiley.

Kelly, G. A. (1991/1955), The Psychology of Personal Constructs. 2 Volumes, Routledge, London/New York, NY (Reprint 1991; Original 1955: Norton, New York, NY).

Langer, R. and Beckman, S. C. (2005), “Sensitive research topics: netnography revisited”, Qualitative Market Research, Vol. 8 No. 2, pp. 189-203. 
Leonard, M. (2003), “Interviews”, in Miller, R. L. and Brewer, J. D. (Eds.), The A-Z of Social Research - A Dictionary of Key Social Science Research Concepts, Sage, London, pp. 166-171.

Mason, J. (2002), “Qualitative interviewing: asking, listening and interpreting”, in May, T. (Ed.), Qualitative Research in Action, Sage, London, pp. 225-241.

Miller, T. W. and Dickson, P. R. (2001), “Online market research”, International Journal of Electronic Commerce, Vol. 5 No. 3, pp. 139-167.

Norton, J. A. and Reynolds, T. J. (2001), "The application of means-end theory in industrial marketing", in Reynolds, T. J. and Olson, J. C. (Eds.), Understanding Consumer Decision Making - The Means-End Approach to Marketing and Advertising Strategy, Lawrence Erlbaum Associates, Mahwah, NJ, pp. 319-334.

O'Connor, H. and Madge, C. (2003), "Focus groups in cyberspace: using the internet for qualitative research", Qualitative Market Research, Vol. 6 No. 2, pp. 133-143.

Olson, J. C. and Reynolds, T. J. (1983), “Understanding consumers' cognitive structures: implications for marketing strategy", in Percy, L. and Woodside, A. G. (Eds.), Advertising and Consumer Psychology, Lexington Books, Lexington, MA, pp. 77-90.

Olson, E. M., Czaplewski, A. J. and Slater, S. F. (2005), "Stay cool”, Marketing Management, Vol. 14 No. 5, pp.14-7.

Peter, J. P., Olson, J. C. and Grunert, K. G. (1999), Consumer Behaviour and Marketing Strategy (European Edition), McGraw-Hill, London.

Pieters, R., Baumgartner, H. and Allen, D. (1995), “A means-end chain approach to consumer goal structures", International Journal of Research in Marketing, Vol. 12, pp. 227-44.

Pieters, R., Botschen, G. and Thelen, E. M. (1998), "Customer desire expectations about service employees: an analysis of hierarchical relations", Psychology \& Marketing, Vol. 15 No. 8, pp. 755-73. 
Pincott, G. and Branthwaite, A. (2000), “Nothing new under the sun?”, International Journal of Market Research, Vol. 42 No. 2, pp. 137-155.

Reynolds, T. J. and Gutman, J. (1988), "Laddering theory, method, analysis, and interpretation", Journal of Advertising Research, Vol. 28, pp. 11-31.

Reynolds, T. J. and Rochon, J. P. (2001), “Consumer segmentation based on cognitive orientations: the Chemlawn case", in Reynolds, T. J. and Olson, J. C. (Eds.), Understanding Consumer Decision Making - The Means-End Approach to Marketing and Advertising Strategy, Lawrence Erlbaum Associates, Mahwah, NJ, pp. 283-298.

Reynolds, T. J., Gengler, C. E. and Howard, D. J. (1995), “A means-end analysis of brand persuasion through advertising", International Journal of Research in Marketing, Vol. 12, pp. 257-66.

Reynolds, T. J., Dethloff, C. and Westberg, S. J. (2001), "Advances in laddering", in Reynolds, T. J. and Olson, J. C. (Eds.), Understanding Consumer Decision Making - The Means-End Approach to Marketing and Advertising Strategy, Lawrence Erlbaum Associates, Mahwah, NJ, pp. 91-118.

Rokeach, M. J. (1973), The Nature of Human Values, Free Press, New York, NY.

Schouten, J. W. and McAlexander, J. H. (1995), "Subcultures of consumption: an ethnography of the new biker", Journal of Consumer Research, Vol. 22 No. 1, pp. 43-62.

Stern, B. B. and Gould, S. J. (1988), “The consumer as financial opinion leader”, Journal of Retail Banking, Vol. 10 No. 2, pp. 43-52.

Stokes, D. and Bergin, R. (2006), "Methodology or "mehodolatry"? An evaluation of focus groups and depth interviews", Qualitative Market Research, Vol. 9 No 1, pp. 26-37.

Strauss, A. and Corbin, J. M. (1998), Basics of Qualitative Research: Techniques and Procedures for Developing Grounded Theory, Sage, Thousand Oaks, CA.

Sweet, C. (2001), "Designing and conducting virtual focus groups", Qualitative Market Research, Vol. 4 No. 3, pp. 130-135. 
Tse, A. C. B. (1999), "Conducting electronic focus group discussions among Chinese respondents", Journal of the Market Research Society, Vol. 41 No. 4, pp. 407-415.

Vriens, M. and Hofstede, F. T. (2000), "Linking attributes, benefits, and consumer values", Journal of Marketing Research, Vol. 12 No. 3, pp. 4-10.

Veludo-de-Oliveira, T. M., Ikeda, A. A. and Campomar, M. C. (2006), "Laddering in the practice of marketing research: barriers and solutions", Qualitative Market Research: An International Journal, Vol. 9 No. 3, pp. 297-306.

Wansink, B. (2000), "New techniques to generate key marketing insights", Journal of Marketing Research, Vol. 12 No. 2, pp. 28-36

Wansink, B. (2003), "Using laddering to understand and leverage a brand's equity", Qualitative Market Research: An International Journal, Vol. 6 (2), pp. 111-18."

Zanoli, R. and Naspetti, S. (2002), "Consumer motivations in the purchase of organic food - a means-end approach”, British Food Journal, Vol. 104 No 8, pp. 643-653. 


\section{Figures}

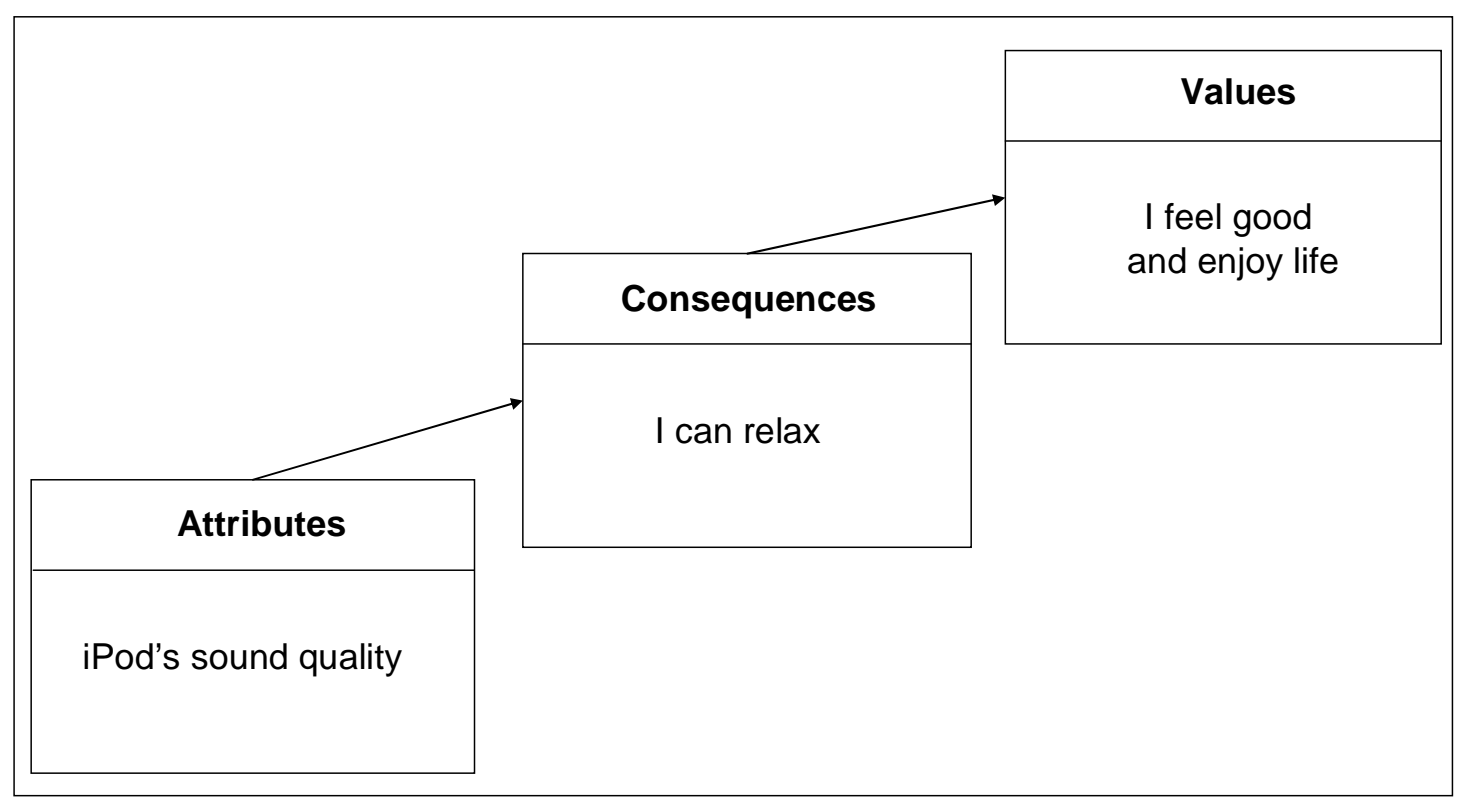

Figure 1. Example for a ladder of abstraction

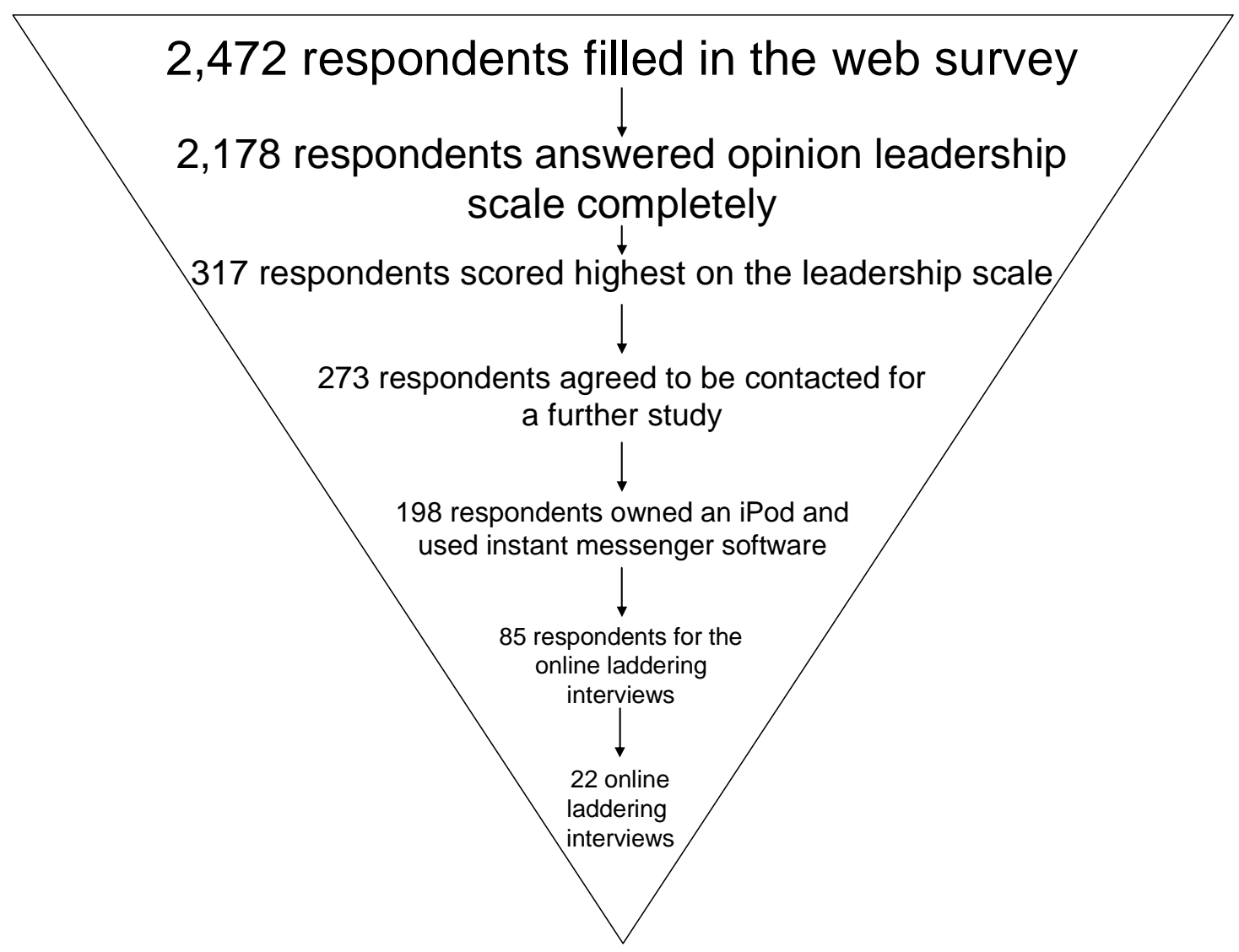


Figure 2. Participants for online laddering interviews identified through a web survey

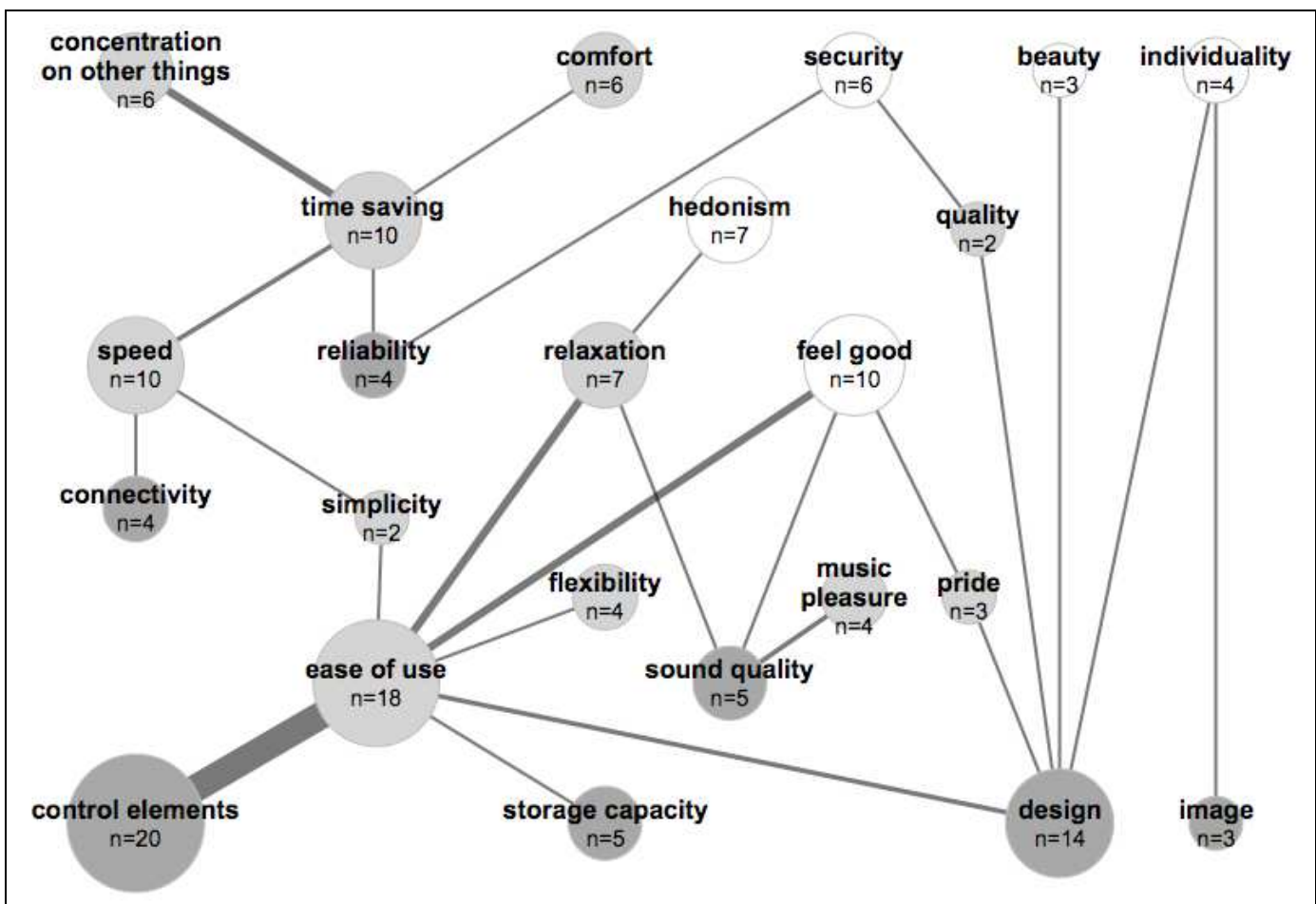

Figure 3. HVM of online laddering interviews (Attributes=Dark, Consequences=Medium and Values=Light) 


\section{Tables}

Interviewer: "Why is it important that the iPod has a scroll-wheel?"

Respondent: "The scroll-wheel is brilliant. I can easily navigate through my song lists"

Interviewer: "Why is it important that the iPod is easy to use?"

Respondent: "It allows me to quickly access my favoured songs"

Interviewer: "Why do want to access your songs quickly?"

Respondent: “I just don't want to waste my time.

Interviewer: "And why do you prefer not to waste your time?"

Respondent: "There are so many things that I have to do throughout the day. I have a really stressful job so I really do not want to spend hours on searching songs on my music player"

Interviewer: "I understand. What do you want to do instead?"

Respondent: You see, I normally use my iPod after work, especially for jogging or so. I just want to relax and enjoy music and the last thing I want is a music player that is difficult to use.

Interviewer: Ok

Table I. Extract from an online laddering interview 